\title{
A review on association between diabetes and thyroid disease
}

\author{
Shailaza Shrestha ${ }^{1}$, Preeti Sharma ${ }^{2 *}$, Pradeep Kumar ${ }^{3}$ \\ ${ }^{\mathbf{1}}$ Assistant Professor, ${ }^{\mathbf{2}}$ Associate Professor, ${ }^{3}$ Professor, Dept. of Biochemistry, ${ }^{1}$ Heritage Institute of Medical Sciences, Varanasi, Uttar \\ Pradesh, ${ }^{2,3}$ Santosh Medical College and Hospital, Ghaziabad, Uttar Pradesh, India \\ *Corresponding Author: Preeti Sharma \\ Email: prcdri2003@yahoo.co.in
}

\begin{abstract}
Two endocrinopathies namely diabetes and thyroid disorders are most often encountered in general population either individually or together mutually influencing one another. Both the disorders have complex biochemical pathophysiology along with hormonal and genetic malfunctions. Thyroid hormones are important regulators of carbohydrate and lipid metabolism, pancreatic function while diabetes affects functioning of thyroid hormones to a variable extent. The main underlying basis of such link could be the interconnections between common signalling pathways among these disorders. Thyroid dysfunctions that are also associated with insulin resistance, when present in diabetic individuals can impair metabolic control. Both hyperthyroidism and hypothyroidism are reported to be associated diabetes mellitus. Researches that investigated the potentiality of thyroid hormone analogues to alleviate obesity, diabetes, and atherosclerosis are also being conducted in clinical practice. This requires a vivid knowledge of this multifarious and complex relationship between diabetes and thyroid hormone so that it can aid in optimisation of treatment modalities in diabetic patients. Thus, in this review article we emphasized on the incidence of thyroid disorders in diabetes and possible links between the two disorders.
\end{abstract}

Keywords: Diabetes, Hypothyroidism, Hyperthyroidism, Euthyroid, Tri-iodothyronine, Thyroxine, Thyroid stimulating hormone.

\section{Introduction}

The thyroid gland which is a butterfly shaped organ present on the front of the neck play important roles in human health and diseases. Thyroid gland produces the hormones commonly called thyroid hormones, viz T3 (triiodothyronine) and T4 (tetra-iodothyronine) that are involved in various cellular metabolic processes and functions, growth and development. Since thyroid hormones affect the metabolism, it can also affect the blood sugar regulation thereby increasing the diabetes risk diabetes or makes it difficult to manage the glycemia if an individual is already presented with diabetes. There occurs a vicious cycle with regards to thyroid disorder and diabetes. The presence of insulin resistance or diabetes doubles the risk of thyroid disorders in an individual while the incidence of thyroid disease in turn can increase the risk of diabetes and metabolic syndrome. ${ }^{1}$

Previous studies have also reported that the alteration in the level of thyroid hormones is associated with diabetes. The first evidence of the association of thyroid dysfunction with diabetes was provided in 1927 by Coller et al. who demonstrated that the glycemic status of diabetic individual deteriorated with hyperthyroidism and surgical removal of some parts of the gland restored the normal glycemia. ${ }^{2}$

Other number of studies also has investigated the complex pathophysiological association between diabetes and thyroid diseases. Hypothyroidism (especially Hashimoto's thyroiditis) and thyroid over activity (chiefly Graves' disease) are mostly shown to be associated with hyperglycemia. Autoimmunity is considered to be the primary cause of thyroid disorder in diabetes mellitus. ${ }^{3}$ Additionally, diabetes mellitus results from inappropriate insulin secretion due to islet cell functional defect or beta cell mass, sedentary living, consumption of high calorie diet or junk foods.

\section{Thyroid hormone and associated disorders}

Thyroid hormones are synthesized in thyroid gland from thyrogloulin and iodine. Initially mono-iodotyrosine (MIT) and di-iodotyrosine (DIT) are formed, which acts as precursors to $\mathrm{T} 3$ and $\mathrm{T} 4$. $\mathrm{T} 4$ is synthesized form combination of two molecules of DIT while T3 is formed from a molecule of MIT and DIT. Production of thyroid hormone is regulated directly by thyroid stimulating hormone (TSH) from anterior pituitary and indirectly by thyrotropin releasing hormone (TRH) form hypothalamus. About $80 \%$ of T3 may be produced from T4 by deiodination in specific tissues. ${ }^{4}$

Alteration in the level of thyroid hormones leads to thyroid disorders. Broadly thyroid disorders may be categorized as hyperthyroidism and hypothyroidism. As the name indicates, hyperthyroidism is the condition where there is excess production of thyroid hormones due to hyper-function of thyroid gland. If the increase in level of thyroid hormone is due to increased secretion instead of production without the incidence of thyroid hyper-function, the condition is known as thyrotoxicosis. The level of T3 and T4 is increased while that of TSH is decreased in hyperthyroidism. ${ }^{5}$ Conversely, in case of hypothyroidism, the levels of thyroid hormones are low while that of TSH is high. Both hyperthyroidism and hypothyroidism can also be categorized as overt or subclinical condition. Overt cases are indicated by the rise or decrease in thyroid hormone levels with subsequent decrease and increase in TSH while subclinical cases are categorised by increase or decrease in the level of TSH with the normal levels of thyroid hormones. In case of subclinical hyperthyroidism $(\mathrm{SCHr})$ TSH is decreased and incase of subclinical hypothyroidism (SCH) TSH is increased. Subclinical thyroid disorders can lead to over diseases in the later stage of life. ${ }^{6}$ 


\section{Prevalence of thyroid disorders in diabetes}

Thyroid disorder shows a variable range of prevalence. In NHANES III study the incidences of hyperthyroidism and hypothyroidism were found to be $1.3 \%$ and $4.6 \%$ respectively while that of subclinical hypothyroidism ranged from 4 to $8.5 \%$. The epidemiological study from Cochin, India reported the prevalence rate of $1.6 \%$ and $1.3 \%$ for subclinical hyperthyroidism and overt hyperthyroidism respectively while for subclinical hypothyroidism and hypothyroidism the rate was respectively $9.4 \%$ and $3.9 \%^{7} \mathrm{~A}$ hospital-based study from Pondicherry demonstrated the incidence rate of $0.6 \%$ and $1.2 \%$ for subclinical hyperthyroidism and overt hyperthyroidism respectively in the participants. ${ }^{8}$

Several previous studies have reported high prevalence of thyroid disorders on diabetic patients. Canaris CJ et al illustrated the prevalence to be $6.9 \%$ and $10.9 \%$ respectively in male and female diabetic patients. ${ }^{9}$ Likewise, Perros $\mathrm{P}$ et al reported the overall prevalence to be $13.4 \%$ with higher prevalence in type 2 diabetic females (31.4\%) compare to diabetic males $(6.9 \%) .{ }^{10}$ In a recent meta analysis study involving 10920 diabetic participants, both type 1 and type 2 diabetic individuals demonstrated similar prevalence rate of thyroid dysfunction, i.e. $11 \% .{ }^{11}$ According to the Greek study, the incidence of thyroid disease was $12.3 \%$ in T2DM with high preponderance in females. A study conducted in Saudi Arabia and Jordan, also reported high incidence of thyroid disorders in diabetic individuals, i.e. $16 \%$ and $12.5 \%$ respectively. ${ }^{12}$

Among the thyroid disorders, subclinical hypothyroidism is the most common disorder observed in diabetes. In a study of Diaz et al, hypothyroidism was prevalent in $18.3 \%$ of diabetic patients compared to $2.9 \%$ in control group. ${ }^{13}$ As per Han $\mathrm{C}$ et al. the incidence of SCH in general population is approximately $2 \%$ and in diabetes is $10.2 \% .^{14}$ The incidence of thyroid dysfunction is also high in pregnant females with high risk of gestational diabetes mellitus. Post partum thyroid dysfunction was seen in $25 \%$ of females with T1DM. ${ }^{15}$ As per Chubb et al the overall prevalence of post partum thyroid dysfunction is $8.6 \%$ in diabetic women. ${ }^{16}$

\section{Effect of thyroid hormones on glucose metabolism and hyperglycemia}

Thyroid hormones are the chief regulators of metabolic processes. They directly influence insulin secretion, insulin sensitivity, carbohydrate metabolism and blood glucose by interacting with different organs like liver, skeletal muscles, adipose tissue and pancreas. ${ }^{17}$ When present at optimal concentration thyroid hormone maintain pancreatic $\beta$-cell integrity and mediate their proliferation. However when present in abnormal concentration, thyroid hormones affect glucose metabolism by different mechanisms. ${ }^{18}$

In case of hypothyroidism, there is decreased hepatic glucose production via glycogenolysis and gluconeogenesis. ${ }^{19}$ Insulin synthesis and release are also reduced in hypothyroidism. Further, hypothyroidism induced receptor defect has also been proposed to be a possible mechanism for decreased insulin mediated peripheral utilisation of glucose.$^{20}$ All these increase the risk of recurrent hypoglycaemia in diabetic patients. [21] Association between hypothyroidism and glucose metabolism (Fig. 1).

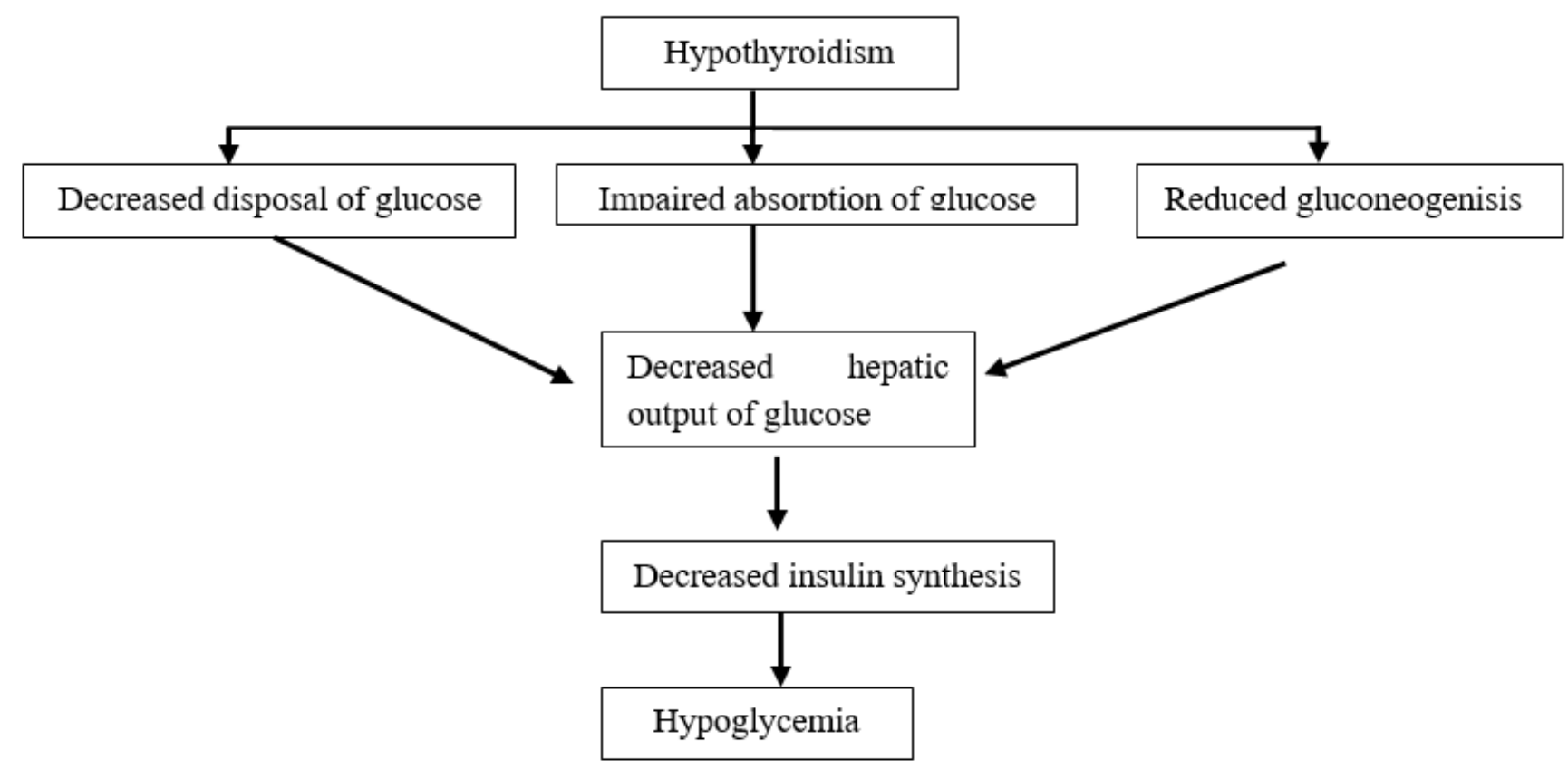

Fig. 1: Hypothyroidism and glucose metabolism 
In Down's syndrome and congenital rubella, T1DM may be associated with hypothyroidism. Some cases of hemochromatosis may be associated with T1DM and hypothyroidism. $^{22}$ Both overt and subclinical hypothyroidism is considered as insulin resistant states. There is down-regulation of glucose transport proteins and increased degradation of insulin (premature) in hypothyroidism. ${ }^{23}$ Treatment of hypothyroidism is shown to restore normal insulin sensitivity and production of glucoregulatory hormones. ${ }^{24}$ Occurance of $\mathrm{SCH}$ in T2DM increases the risk of diabetic nephropathy which could be due to decreased cardiac output or increased peripheral vascular resistance that ultimately decreased renal blood flow and GFR (glomerular filtration rate) ${ }^{25}$ A recent study conducted by Yang et al showed that $\mathrm{SCH}$ in diabetes leads to severe retinopathy compared to euthyroid diabetic patients. Treatment of $\mathrm{SCH}$ improves renal function and also reduces the risk of retinopathy in diabetes. ${ }^{26}$

In case of hyperthyroidism, there is increase in insulin resistance and production of glucose. Hyperthyroidism stimulates endogenous production of glucose by several mechanisms as follows:

1. Increasing availability of lactate, alanine and glutamine (from skeletal muscles), and glycerol (from adipose tissue) all of which are gluconeogenic precursors.

2. Stimulating gluconeogenesis by increasing concentration of free fatty acids. ${ }^{20}$
3. Increasing hepatic glycogenolysis causing increased glucose output from liver even in well fed condition.

4. Upregulating expression of glucose transporter proteins in hepatocytes thereby permitting efflux of glucose from cells that further favours gluconeogenesis. ${ }^{27}$

5. Increasing secretion of hyperglycaemic hormones like glucagon, catecholamines and growth hormones. ${ }^{28}$

6. Increasing intestinal absorption of glucose. ${ }^{29}$

Though hyperthyroidism is linked with insulin resistance, it is shown to increase the secretion of insulin. However, in hyperthyroidism the insulin is secreted as an inactive precursor which is rapidly degraded causing reduction in insulin half life. Some studies have documented that hyperthyroidism is associated with defective proinsulin processing as indicated by decreased $\mathrm{C}$ peptide: pro-insulin ratio. ${ }^{30}$ As per Falzacappa et al, T3 when present at normal physiological concentration maintains size and consistency of pancreatic islets ${ }^{18}$ and facilitates secretion of active insulin whereas augmentation in T3 level causes defective proliferation of islets cells and synthesis of inactive insulin resulting in insulin resistant state. Association between hyperthyroidism and glucose metabolism (Figure 2) and the mutual association of diabetes and thyroid dysfunction (Table 1).

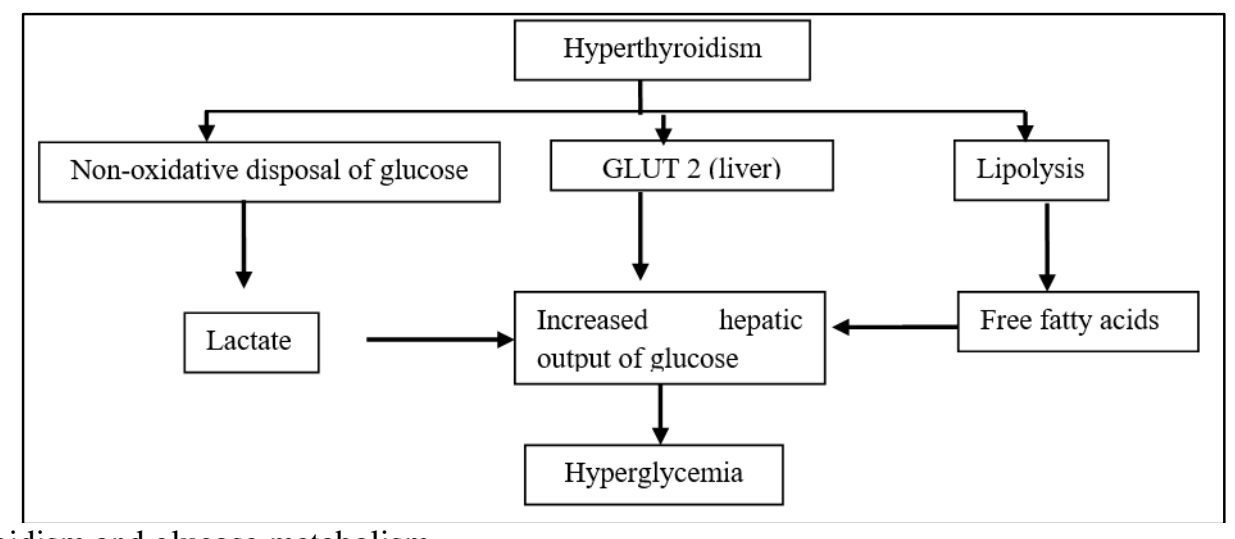

Fig. 2: Hyperthyroidism and glucose metabolism

Table 1: Mutual association between diabetes and thyroid

\begin{tabular}{|c|c|c|}
\hline Clinical profile & Influence on glycemia & $\begin{array}{c}\text { Effect on thyroid function or thyroid } \\
\text { disorder }\end{array}$ \\
\hline $\begin{array}{l}\text { Diabetes mellitus (euthyroid } \\
\text { individuals) }\end{array}$ & - & $\begin{array}{c}\mathrm{T} 3 \downarrow, \mathrm{rT} 3 \uparrow \\
\downarrow \text { Response of TSH to TRH } \\
\text { Impairment in nocturnal TSH peak }\end{array}$ \\
\hline $\begin{array}{l}\text { Diabetes mellitus (hyperthyroid } \\
\text { individuals) }\end{array}$ & Poor control of glycemia & $\uparrow$ dysthyroid optic neuropathy \\
\hline $\begin{array}{l}\text { Hyperthyroidism (normoglycemic } \\
\text { individuals) }\end{array}$ & $\begin{array}{l}\text { Glucose intolerane (50\% of } \\
\text { cases) }\end{array}$ & - \\
\hline Hyperthyroidism (diabetic individuals) & Deteriorates control of diabetes & - \\
\hline Hypothyroidism (diabetic individuals) & $\begin{array}{c}\text { Predisposes recurrent } \\
\text { hypoglycaemia }\end{array}$ & - \\
\hline Autoimmune (T1DM) & - & $\uparrow$ incidence of disease \\
\hline
\end{tabular}




\section{Diagnosis and treatment of thyroid in diabetes}

Both diabetes and thyroid disorders are suggested to have a similar genetic background. As per recent data single nucleotide genetic polymorphism (Threonine92Alanine polymorphism) polymorphism in deiodinase gene is associated with increased diabetic risk. ${ }^{31}$

Diabetes affects thyroid function at two basic levels:

1. At the level of hypothalamus which controls the secretion of TSH. In diabetes response of TSH to TRH is impaired.

2. At peripheral tissues where $80 \%$ of $\mathrm{T} 4$ is converted to T3. ${ }^{32}$

Thyroid disorder in diabetes can be assessed by evaluating thyroid function test (TFT) that comprises the measurement of T3, T4 and TSH. However, the presence of hyperglycaemic state may impair the appropriate diagnosis and interpretation of TFT in the individuals with uncontrolled diabetes. Therefore American thyroid association has recommended frequent screening of T2DM patients for the presence of thyroid disorders. ${ }^{33}$ Overview of recommended guidelines is provided (Table 2). Similarly, Kadiyala et al proposed a simplified approach in which the authors suggested:

1. Measurement of TSH and TPO (thyroproxidase antibody) in all the diabetic patients

2. Subsequent annual testing in case of T1DM with TSH level at upper limit or positive antibodies (Fig. 3). ${ }^{11}$

Table 2: Screening guidelines for thyroid problems in diabetes

\begin{tabular}{|c|c|c|}
\hline Guidelines & Type 2 diabetes mellitus & Recommendations \\
\hline $\begin{array}{ll}\text { American } & \text { Thyroid } \\
\text { Association, 2000 } & \end{array}$ & $\begin{array}{l}\text { Diabetic patients may require frequent } \\
\text { testing }\end{array}$ & $\begin{array}{l}\text { TSH measurement from } 35 \text { yrs and at every } \\
5 \text { yrs intervals in all adults; Person at high } \\
\text { risk requires more frequent testing }\end{array}$ \\
\hline $\begin{array}{ll}\text { American } & \text { Association of } \\
\text { Clinical } & \text { Endocrinologists } \\
\text { Thyroid disease clinical } \\
\text { Practice, } 2002\end{array}$ & $\begin{array}{l}\text { Thyroid palpation and } \mathrm{TSH} \\
\text { measurement at diagnosis and also at } \\
\text { regular intervals (especially if present } \\
\text { with goitre or other autoimmune } \\
\text { diseases) }\end{array}$ & No specific recommendation (for T2DM) \\
\hline $\begin{array}{ll}\text { American } & \text { Association of } \\
\text { Clinical } & \text { Endocrinologists, } \\
2007 & \end{array}$ & Not specifically mentioned & $\begin{array}{l}\text { Thyroid function test in pregnant females } \\
\text { with diabetes }\end{array}$ \\
\hline $\begin{array}{lr}\text { American } & \text { Diabetes } \\
\text { Association. Standards of } \\
\text { medical care in diabetes, } 2009\end{array}$ & Not specifically mentioned & $\begin{array}{l}\text { Thyroid palpation (all diabetic patients); } \\
\text { TSH > 50 years adults, or in dyslipidemic } \\
\text { patients }\end{array}$ \\
\hline $\begin{array}{l}\text { British Thyroid Association, } \\
2006\end{array}$ & $\begin{array}{l}\text { TFT at baseline (routine annual TFT not } \\
\text { recommended) }\end{array}$ & $\begin{array}{l}\text { Assessment of TSH and antibodies during } \\
\text { pregnancy and at postpartum state in } \\
\text { diabetic females }\end{array}$ \\
\hline
\end{tabular}

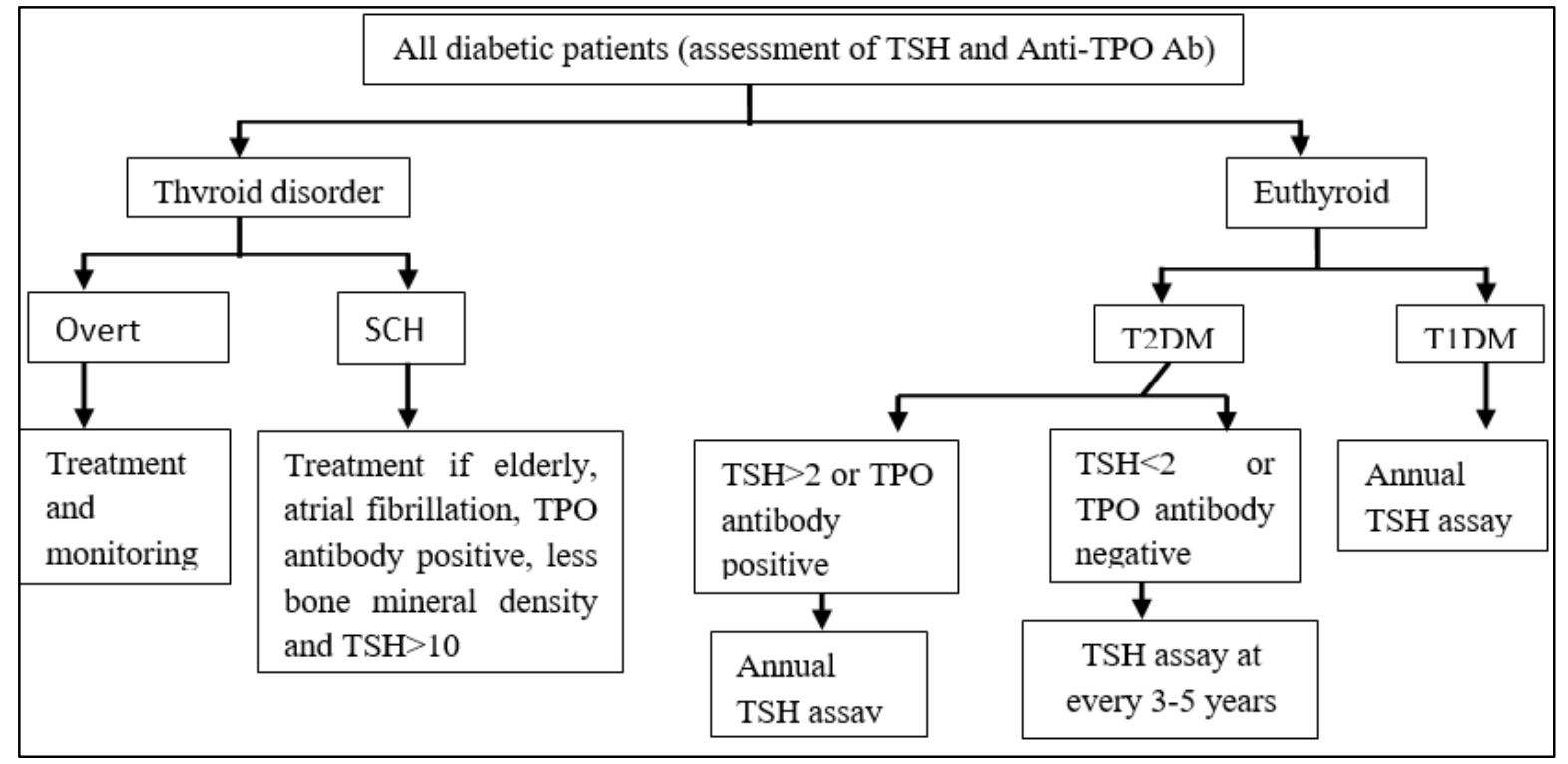

Fig. 3: Screening and monitoring of thyroid function in diabetes 
Metformin, a common anti-diabetic drug suppresses the secretion of TSH in hypothyroid patients. The suppression usually reverts 3 months after the withdrawal of drug. Further, the development of several thyroid hormone analogues has made it possible to establish novel strategies for the management of diabetes.

\section{Conclusion}

Thyroid disorders are common in diabetic patients. Though the efforts are being increasingly made to unravel the pathophysiological mechanisms involved, there is still a requirement of further in-depth studies. Thyroid dysfunctions if untreated can impair metabolic processes and further increase CVD risk in diabetes. SCH is the most commonly observed thyroid disorder in diabetes and confers greater risk of associated complications. Thus it is very important to diagnose thyroid disorder in diabetic patients and screening should also be recommended in routine practice in diabetic care. It is necessary from the part of clinician to identify the high-risk diabetic groups and manage the thyroid abnormalities if present as early as possible to minimize the risk of further complications.

\section{Source of funding}

None.

\section{Conflict of interest}

None.

\section{References}

1. Radaideh AR, Nusier MK, Amari FL, Bateiha AE, El-Khateeb MS et al. Thyroid dysfunction in patients with type 2 diabetes mellitus in Jordan. Saudi Med J 2004;25(8):1046-50.

2. Mishra M, Sotto MR, Panta R, Miyares M, Solanki R. Association of Diabetes Mellitus and Thyroid Disorders: A Metabolic Prospective. Asian Pac J Health Sci 2017;4(3):25362.

3. Wang C. The Relationship between Type 2 Diabetes Mellitus and Related Thyroid Diseases. J Diabetes Res 2013;2013:390534

4. Monaco F. Classification of thyroid diseases: suggestions for a revision. J Clin Endocrinol Metab 2003;88(4):1428-32.

5. Nazir. S., Sharma P., Itagappa M, Kumar P, Sharma R. Evaluation of metabolic syndrome as complication in thyroid patient in Ghaziabad. Indian J Public Health Res Dev 2015:6(4):104-7.

6. Reilly DS. Thyroid function tests-time for reassessment. $B M J$ 2000;320(7245):1332-4.

7. Menon VU, Sundaram KR, Unnikrishnan AG, Jayakumar RV, Nair V, Kumar H. High prevalence of undetected thyroid disorders in an iodine sufficient adult south Indian population. J Indian Med Assoc 2009;107(2):72-7.

8. Abraham R, Murugan VS, Pukazhvanthen P, Sen SK. Thyroid Disorders in Women of Puducherry. Indian J Clin Biochem 2009;24(1):52-9.

9. Gupta G, Sharma Preeti, Kumar P, Sharma R. Cardiovascular risk in patients with mild to severe Subclinical hypothyroidism. Asian J Pharm Clin Res 2016;9(1):1-3

10. Perros P, McCrimmon RJ, Shaw G, Frier BM. Frequency of thyroid dysfunction in diabetic patients: value of annual screening. Diabet Med 1995;12(7):622-7.
11. Kadiyala R, Peter R, Okosieme OE. Thyroid dysfunction in patients with diabetes: clinical implications and screening strategies. Int J Clin Pract 2010;64(8):1130-9.

12. Akbar DH, Ahmed MM, Al-Mughales J. Thyroid dysfunction and thyroid autoimmunity in Saudi type 2 diabetics. Acta Diabetol 2006;43(1):14-8.

13. Díez JJ, Iglesias P. An analysis of the relative risk for hypothyroidism in patients with Type 2 diabetes. Diabet Med 2012;29(12):1510-4.

14. Han C, He X, Xia X, Li Y, Shi X, Shan Z, Teng W. Subclinical Hypothyroidism and Type 2 Diabetes: A Systematic Review and Meta-Analysis. PLoS One 2015;10(8):e0135233.

15. Gerstein HC. Incidence of postpartum thyroid dysfunction in patients with type I diabetes mellitus. Ann Intern Med 1993;118(6):419-23.

16. Chubb SA, Davis WA, Inman Z, Davis TM. Prevalence and progression of subclinical hypothyroidism in women with type 2 diabetes: the Fremantle Diabetes Study. Clin Endocrinol (Oxf) 2005,62(4):480-6.

17. Mullur R, Liu YY, Brent GA. Thyroid Hormone Regulation of Metabolism. Physiol Rev 2014;94(2):355-82.

18. Falzacappa VC, Panacchia L, Bucci B, Stigliano A, Cavallo MG, Brunetti E, et al. 3,5,3'-triiodothyronine (T3) is a survival factor for pancreatic beta-cells undergoing apoptosis. $J$ Cell Physiol 2006;206(2):309-21.

19. Falzacappa VC, Mangialardo C, Raffa S, Mancuso A, Piergrossi P, Moriggi G, et al. The thyroid hormone T3 improves function and survival of rat pancreatic islets during in vitro culture. Islets 2010;2(2):96-103.

20. Dimitriadis G, Raptis SA. Thyroid hormone excess and glucose intolerance. Exp Clin Endocrinol Diabetes 2001;109(suppl 2):S225-S39.

21. Mohn A, Di Michele S, Di Luzio R, Tumini S, Chiarelli F. The effect of subclinical hypothyroidism on metabolic control in children and adolescents with Type 1 diabetes mellitus. Diab Med 2002;19(1);70-3.

22. Donckier JE. Endocrine diseases and diabetes. In: Text book of Diabetes mellitus. Pickup JC, Williams G (eds), Blackwell Publishing Company, Chichester, 2003:27.1- 27.25.

23. Maratou E, Hadjidakis DJ, Kollias A, Tsegka K, Peppa M, Alevizaki M, et al. Studies of insulin resistance in patients with clinical and subclinical hypothyroidism. Eur J Endocrinol 2009;160(5):785-90.

24. Brenta G, Danzi S, Klein I. Potential therapeutic applications of thyroid hormone analogs. Nat Clin Pract Endocrinol Metab 2007;3(9):632-40.

25. Chen HS, Wu TE, Jap TS, Lu RA, Wang ML. Subclinical hypothyroidism is a risk factor for nephropathy and cardiovascular diseases in Type 2 diabetic patients. Diabet Med 2007;24(12):1336-44.

26. Yang GR, Yang JK, Zhang L, An YH, Lu JK. Association between subclinical hypothyroidism and proliferative diabetic retinopathy in type 2 diabetic patients: a case-control study. Tohoku J Exp Med 2010;222(4):303-10.

27. Mokuno T, Uchimura K, Hayashi R. Glucose transporter concentration in hyper and hypothyroid rat livers. J Endocrinol 1999;160(2):285-9.

28. Olaleye SB, Elegbe RA. Catecholamines potentiate the effect of thyroid hormone on intestinal absorption of glucose in the rat. Afr J Med Med Sci 2005;34(2):177-83.

29. Orihuela D. Inhibitory effect of aluminium on calcium absorption in small intestine of rats with different thyroid hormone status. J Inorg Biochem 2009;103(11):1542-7.

30. O'Meara NM, Blackman JD, Sturis J, Polonsky KS. Alterations in the kinetics of C-peptide and insulin secretion in hyperthyroidism. J Clin Endocrinol Metab 1993;76(1):79-84. 
31. Dora JM, Machado WE, Rheinheimer J, Crispim D, Maia AL Association of the type 2 deiodinase Thr92Ala polymorphism with type 2 diabetes: case-control study and meta-analysis. Eur J Endocrinol 2010;163(3):427-34.

32. Gursoy NT, Tuncel E, Erturk E, Imamoglu S, Arinik A. The relationship between the glycemic control and the hypothalamus-pituitary-thyroid axis in diabetic patients. Turk $J$ Endocrinol Metab 1999;163-8.

33. Ladenson PW, Singer PA, Ain KB, Bagchi N, Bigos ST, Levy EG, et al. American Thyroid Association guidelines for detection of thyroid dysfunction. Arch Intern Med 2000;160(11):1573-5. 